\title{
ОСОБЕННОСТИ РАННЕСРЕДНЕВЕКОВОГО ЭПИЧЕСКОГО ТВОРЧЕСТВА АРАБОВ
}

\author{
Ph.D. (филологические науки) Муталова Гулнора Сатторовна \\ Ташкентский государственный институт востоковедения, \\ и. о. доцента кафедры арабской филологии, Узбекистан, Ташкент.
}

DOI: https://doi.org/10.31435/rsglobal_ijitss/31012019/6326

\section{ARTICLE INFO}

Received 25 November 2018

Accepted 21 January 2019

Published 31 January 2019

\section{KEYWORDS}

tribal oral tradition, the epic tradition, "Days of the Arabs", cyclization, the epic hero," exactness and fantastic", fiction.

\begin{abstract}
The article is devoted to the most interesting phenomenon in Arabic literature - tribal legends, included in the Arab medieval literature called "Ayyam alArab" ("Days of the Arabs"). Oral narrative is an incomparable genre of Arab culture. Containing folklore origins and genetically related to the epic, it is at the same time quite distinctive and distinctly separate from other literary genres. The prose of Days, as well as poetry, is a work of high art with its own laws and its own poetics. And considering that for a long time, Arabic prose has not received proper development, the appearance of Ayyam AlArab should be regarded as one of the sources of historiographic prose, actually as the beginning of narrative prose in the history of Arabic literature.
\end{abstract}

Citation: Муталова Гулнора Сатторовна. (2019) Osobennosti Rannesrednevekovogo Ehpicheskogo Tvorchestva Arabov. International Journal of Innovative Technologies in Social Science. 1(13). doi: 10.31435/rsglobal_ijitss/31012019/6326

Copyright: (C) 2019 Муталова Гулнора Сатторовна. This is an open-access article distributed under the terms of the Creative Commons Attribution License (CC BY). The use, distribution or reproduction in other forums is permitted, provided the original author(s) or licensor are credited and that the original publication in this journal is cited, in accordance with accepted academic practice. No use, distribution or reproduction is permitted which does not comply with these terms.

Введение. Важнейшей частью культурного и духовного наследия различных народов мира являются предлитературные эпические памятники, среди которых особого внимания заслуживают уникальные и бесценные образцы устного народного творчества. Для арабов одним из таких памятников являются племенные сказания, получившие в арабистике название «Аййам ал-араб» («Дни арабов»). Собрание сказаний о подвигах арабских племен и отдельных героев со вставленными стихотворными отрывками, уникально и как литературный источник, изучение некоторых составных элементов которого доказали существование арабского эпоса, который можно поставить в один ряд с лучшими образцами мирового эпического творчества. Помимо этого, «Дни арабов» послужили сюжетным кладезем и продолжают оставаться живительным источником вдохновения для многих поэтов и писателей и не только на Востоке, но и на Западе.

В доисламский период на территории Аравийского полуострова поддерживалась и развивалась богатая эпическая традиция, составившая органичную часть единого и сложного целого общеарабского, пусть ещё не превратившегося в классический образец, героического эпоса. Появившиеся позднее «арабские народные романы» были естественным продолжением этой традиции, получив рост на её почве. Преемственность носила чисто культурный характер, в ней выражалось осознание исторической связи с общеарабским прошлым. Эпос не принадлежит одному времени, но является достоянием многих сменяющих друг друга поколений.

Результаты исследования. Предания «Аййам ал-араб» («Дни арабов») рисуют нам целую эпоху в жизни арабов - эпоху родоплеменных отношений, тем самым, представляя собой бесценный исторический памятник. Ни одно из них не стоит обособленно. Все они дополняют друг друга в создаваемой ими картине мира. Каждый рассказ - законченное целое и вместе с тем, он связан с другими. Происходит как бы беспрерывная циклизация. 
Употребляемый нами термин не следует путать с термином «циклизация», принятым В. Жирмунским, Н. Ибрагимовым и Т. Мухтаровым.

Так, Н. Ибрагимов в книге «Арабский народный роман» пишет: «Наиболее простым случаем циклизации, вызванным повышением интереса к тому или иному герою народных сказаний, возникающему в определенных исторических ситуациях, является соединение разрозненных повествований, прозаических и поэтических об отдельных подвигах этого героя. При этом возникает единая сюжетная линия, на которую эти сюжеты, иногда дублируясь с незначительными вариантами, нанизываются» [7, с. 62].

По мнению Т. Мухтарова и др. «суть принципа циклизации состоит в том, что в начале разрозненные легенды и предания о том или ином герое объединяются в циклы, группирующиеся вокруг одной центральной фигуры» [11, с. 115].

Согласно теории В. Жирмунского, процесс циклизации можно разделить на три основных вида: биографическая, генеалогическая и циклизация вокруг единого центра [6]. В эпосе, как правило, происходит объединение разрозненных рассказов об одном герое (или племени) вокруг единого сюжетного стержня. Эти рассказы о подвигах выстраиваются в логически последовательное повествование о жизни героя - от его рождения до героической гибели. Позднее, когда герою как бы досочиняются предки, биографическая циклизация перерастает в генеалогическую, которая предполагает гибель героя и последующую месть его родственников врагу.

В рассматриваемом нами памятнике циклизация осуществляется за счет структурного единства преданий, собранных в единую ткань, благодаря единству тематики, прикрепленности сюжета «Дней» к реальному географическому пространству, вхождению одного «Дня» в другой со всеми вытекающими отсюда генетическими связями. Летопись дополнялась новыми сведениями, её окончание всё время отодвигалось, продолжаясь дополнительными рассказами о новых событиях. Летопись росла вместе с историей.

Интересно отметить, что, несмотря на то, что предания «Аййам ал-араб» являлись по существу «местными хрониками», о них было известно по всей территории Аравийского полуострова, они были общеарабским достоянием. Наверняка, были и другие «Дни», повествующие о бесчисленных межплеменных сражениях, разыгравшихся в доисламской Аравии, но они не сохранились, стерлись из памяти. Какой критерий был избран при отборе из огромного количества преданий тех, что получали право на дальнейшее существование. По всей вероятности, сохранялись и «выживали» лишь те из преданий, что повествовали о событиях и битвах, отличающихся от многочисленных других столкновений наличием определенного комплекса факторов.

Первым фактором могло служить участие в сражении известного исторического лица ${ }^{1}[11$, с. 84-110]. Например, «День Халимы» и «'Айн 'Убаг» с участием известных правителей джахилийского периода ал-Мунзира ибн Ма ас-Сама' и ал-Хариса ибн Джабалы, «День 'Указ» с участием самого пророка Мухаммада (с.а.в).

Вторым фактором, обусловившим сохранение предания, могло бы быть участие в «Дне» талантливого поэта, воспевавшего подвиги своих соплеменников, увековечив их в своих стихах. Это - знаменитые доисламские поэты Антара ибн Шаддад / «День Дахиса и Габры»/, Имруулькайс / «День Худжра»/, ал-Ханса и её братья Му'авийя и Сахр / «Первый день Хауза», «День Зат ал-Асл»/.

Третьим фактором являются затянувшиеся столкновения и войны, длившиеся годами «Войны ал-Фиджар», и десятилетиями «Война ал-Басус» и «День Дахиса и ал-Габры».

К четвертому фактору следует отнести то, что сражение, о котором повествовало предание, играло большую роль в истории арабов, являясь каким-то важным переломным моментом в соотношении определенных сил. Например, «День Зи Кар», когда объединенные арабские племена нанесли мощное поражение иранским войскам, или «День Хазаз», повествующий как после объединения усилий всех северо-аравийских племен удалось покончить с зависимостью северных арабов от южных.

Конечно, перечисленные факторы являются не исчерпывающими при естественном отборе лучших преданий. Ведь сохранились лишь те, что выдержали испытания временем и получили одобрение слушателей. Все остальные, менее совершенные варианты сказаний были

\footnotetext{
1 Это ещё один пример эпической традиции, продолжившейся в народных романах, где главным героем часто является историческая личность, например, "сират Хамза", ”сират Антара", ”сират Бейберс", "сират Бахлаван" и т.д.
} 
отброшены и отвергнуты. Предметом изображения в преданиях, прошедших эту «примитивную» цензуру служит не быт, не повседневная жизнь людей, а решающие поворотные моменты в судьбах арабских племен, оставаясь на века в народной памяти.

Всеми исследователями, занимавшимися дописьменным периодом, отмечалось наличие в этот период двух типологически противоположных друг другу линий текстов. Первая определяется как мифологическая, а вторая - устные рассказы о происшествиях. По определению С.С.Аверинцева, «мифы - представляют собой цельную систему, в терминах которой воспринимается и описывается весь мир» [2, с. 876]. Другими словами, «миф - это осмысление мира и эмоциональное вживание в его явления, но никоим образом не жанр словесности» [4, с. 17]. Мифологические тексты «не являются, в нашем смысле сюжетным, и вообще с большим трудом могут быть описаны средствами привычных для нас категорий. Мифологический текст наблюдает категориями начала и конца, он мыслится как «целое, непрерывно повторяющееся устройство, синхронизированное с циклическими процессами природы» [9, с. 11].

В нашем исследовании нас интересует вторая линия текстов, которая как бы разрывает непрерывный мифологический текст и выхватывает из заданного цикла жизни редкие события, привлекающие к себе внимание своей неповторимостью. Эти тексты в отличие от первых уже сюжетны и именно на их основе возникает рассказ. К примеру, события в «Дне Халимы», который получил свое название в честь дочери ал-Хариса ибн Джабала ал-Гассана, одержавшего победу в сражении ал-Мунзира. Дочь ал-Хариса внесла свой важный вклад в эту победу, по-видимому, вдохновляя своей внешностью воинов отца. Здесь немного воображения и можно представить себе «сюжет» достойный «1001 ночи» - вождь племени мог пообещать особо отличившемуся воину свою дочь в качестве награды.

Говоря о критериях отбора событий в «Днях», мы отметили, что в них запечатлелось только самое яркое, необычное, редкое, привлекающее внимание в мире, окружающем человека, и в самом человеке. И это естественно.

По существу, основная тема преданий «Аййам ал-араб» - это конфликты между арабами, приводящие к кровавым распрям, убийствам, ранениям, изгнаниям из племени. В каждой отдельной ситуации события переплетаются и взаимодействуют с множеством факторов, характерных для каждого конкретного случая. Поэтому и невозможно было бы систематизировать «дни» на основе этого признака. Какие-либо детали из жизни ведущих персонажей могли быть упомянуты лишь по мере необходимости для раскрытия главного конфликта.

«Дни» более чем другие жанры средневековой литературы подходят к изображению действительной жизни. Они доносят до нас реальные конфликты и ситуации, её герои и персонажи в большинстве своем, это люди, которые тогда жили на самом деле. «Автор» «Дней» убежден в их правдивости, так же, как и его слушатели. Однако, отметим, что в средневековую реальность входило и немало фантастического и чудесного. Так, в преданиях наряду с живыми людьми присутствуют джины, среди факторов, определяющих ход сражений. Важное место занимают предсказания и вещие сны. Обо всем этом преподносится в той же степени уверенности, что и обычные сцены, и разговоры, то есть предсказания и вещие сны воспринимается как что-то обыденное, естественное.

Например, в «День Тихфа», рассказывается, что у главного героя Шихаба был джин, который обо всем рассказывал ему $[1$, с. 80$]$. Он же предсказал, что Шихаб выиграет спор и получит 100 верблюдов. Так и произошло на самом деле. Или в «Первом дне Хауза» Сахр отговаривает своего брата Му'авийю от набега словами: «Я вижу, как тебя повесят на акации, если ты нападешь на них. Но не послушал Му'авийя и ушел в набег. Едва он достиг долины Хауза, над ним стала кружить птица, а ночью приснились ему антилопа и ворон. Показалось ему это плохим предзнаменованием, и вернулся он домой. Через год вновь собрался он войной на чужое племя, и опять привиделись ему на том же месте и антилопа, и ворон. Снова повернул он коня обратно...» [1, с. 221]. И все же не удалось Му'авийе уйти от судьбы, не смог избежать он боя с противником, и был убит.

Судьба играет важную роль в жизни и сознании арабов в доисламский период. Именно с ней тесным образом связаны прорицания, видения и вещие сны. Судьба - это сила, стоящая над человеком, она подстерегает его на каждом шагу, властвуя над живой и мертвой природой. У каждого человека своя судьба, которая не зависит от его внутренних качеств и характера. Нередко самые мудрые и сильные герои преданий терпят поражения в схватке с судьбой.

Ярким примером тому служит предание о жизни и гибели Имруулькайса в «День Худжра» $[1$, с. 80$]$. Когда пришли к нему с вестью о смерти отца, то долго думал он, прежде чем принять решение об отмщении. К тому времени отношения между отцом и сыном были 
давно расстроены, так как отцу не нравилось, что Имруулькайс, имея в своих жилах царскую кровь, слагает стихи. Старшие братья отказались от мести, и на долю отвергнутого сына пал выбор оставить или нет кровь отца неотомщенной.

«...Решил тогда Имруулькайс погадать на стрелах, которых было три: «повелевающая», «запрещяающая» и «выюсидающая». Три раза выпускал он стрелы, и три раза выпадала ему «запрещающая» стрела. Тогда обломал он стрель, кинул их в лищо идола, при помощи которого он гадал и сказал: «Если б у тебя был убит отеи, ты не препятствовал бы мне»»»[1, с. 97-98].

По сюжету предания все отговаривали Имруулькайса от мести, предлагая получить царский выкуп. Но судьба уготовила ему другой исход: Имруулькайс мстит за смерть отца и, вынужденный скрываться от преследований врагов, находит пристанище у византийского императора ас-Самавала в Тайме. Тот дает ему многочисленное войско и отпускает. Но когда Имруулькайс покидает царский двор, то на него клевещут завистники, и тот посылает вдогонку поэту отравленное расшитый золотом халат. Одев его, Имруулькайс погибает.

На первый взгляд, кажется, будто Имруулькайс сам создает ситуации и влияет на ход событий. Но на самом деле судьба его неизбежна, ему было предначертано погибнуть, и он погибает. Эпизод со стрелами служит для уведомления публики о предстоящей судьбе Имруулькайса. Это предвосхищение событий выступает в виде прорицания, что прибавляет повествованию напряженность и интерес: всем интересно узнать, как именно свершится предначертанное ему судьбой.

Тема судьбы постоянно присутствует в «Днях». Конечно, «Дни» не дают ясного представления о причинах удачи или невезения человека, и Имруулькайс, в рассматриваемом нами предании служит образцом человека, который терпит неудачу в столкновении с судьбой, несмотря на свои выдающиеся качества.

«День Худжра» интересен тем, что содержащиеся в нем сюжеты троекратного гадания, коварного царя, завистника, отравленной одежды весьма близки к сказочным. А. Веселовский, опираясь на сравнительную этнографию, пытался наметить последовательность развития мотивов-сюжетов, отражающих последовательные ступени развития общества [3].

В «Днях» нет «свободного» вымысла. Нет в них выраженной авторской позиции, что даёт право говорить об «объективности» изображения событий и персонажей. Эти черты, связанные друг с другом являются признаками эпического творчества. В «Днях» мы не найдем обнаженного вымысла, потому что важным требованием к ним было требование соблюдения точности. Эта черта, в целом, присуща эпосу, и не только арабскому.

Говоря о точности изображения действительности, необходимо отметить, что факты не просто констатируются, о событиях не просто сообщается, а все события описываются. И в этом проявляется реалистичность «Дней», где картина происходящих событий реальна и во времени и в пространстве, она живая и убедительная. Однако эту реалистичность нельзя отождествлять с «документальностью». «Документальность», «протокольность» не изображают действительность, а слепо её отражают, фотографируют её лишь в отдельных частях. В художественном изображении воссоздаётся действительность, рассказы о событиях наглядны, легко вообразимы и представимы.

Известный востоковед Б. Я. Шидфар в книге «Образная система арабской классической литературы» пишет о сочетании «точности с фантастичностью», характерном для героического эпоса $[12$, с. 60]. Подобная «точность» прослеживается во всех «Днях»: подробно перечисляется количество воинов, с их подробной характеристикой и описанием внешности каждого из них, как, например, в «Первый день Хауза». Обратимся к отрывку из этого предания, где женщина из племени джухайна описывает Му'авийю и его спутников своим союзникам из бану мурра:

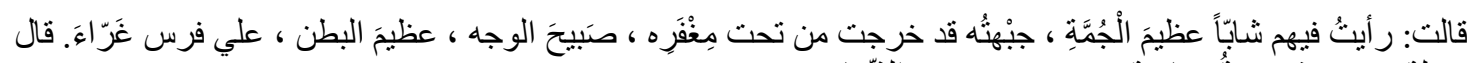

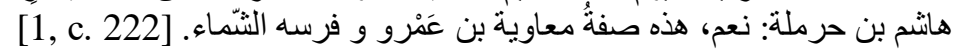

Она сказала: Я видела среди них юношу с густой шевелюрой, лоб его выступает изподилема, лицо его красиво, у него широкая грудь, а конь под ним белого ивета. Сказал Хашим ибн Хармала: Да, это Му'авийя ибн 'Амр и его конь аш-Шама'.

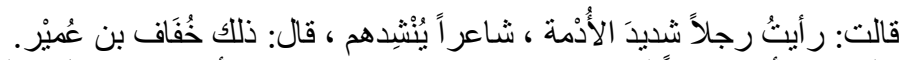

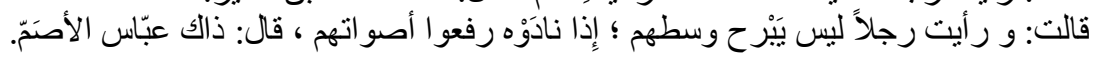




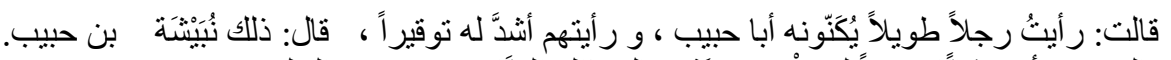

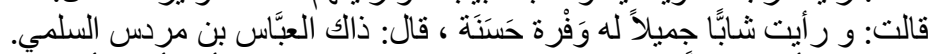

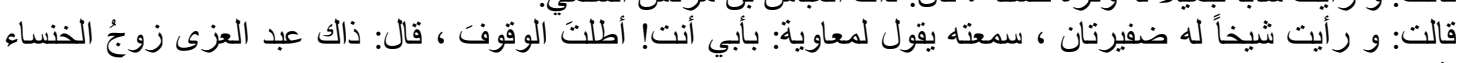

$$
\begin{aligned}
& \text { أخت معاوية و صخر . [1, c. 222] }
\end{aligned}
$$
ибн Умайр.

Она сказала: Один из них был очень смуглый, он читал стихи. Он ответил: Это Хуфаф

Она сказала: Я видела человека, он не покидал центра, и если звали его, то повышали голос. Он ответил: Да, это Аббас ал-Асамма.

Она сказала: Я видела юношу высокого роста, его звали Абу Хабиб, я заметила у них большое почтение к нему. Он ответил: "Да, это Нубайта ибн Хабиб».

Она сказала: Я видела красивого юношу, уж очень хорош собой. Он ответил: Это алАббас ибн Мирдас ас-Салма.

Она сказала: Я видела старика, у которого были две косы. Я сльшала, как он говорил Му'авийе: Поехали! Сколько можно ждать? Онсказал: Это Абду ал-'Аза - муж ал-Хансы, сестры Му'авийи и Сахра.

В «Дне ал-Лива» можно встретить и такое описание племен. Здесь рассказывается о том, как «племена бану джушам и бану наср, возглавляемые сыновьями Му“авийи ибн Бакра нападали на племена гатафан, победили в битве и забрали их имущество. Пройдя немного пути, они решили остановиться и отдохнуть. Один из братьев стал убеждать другого, что привал делать ещё рано, так как гатафанцы могут устроить погоню. Не послушав его, они стали варить похлебку из верблюдицы, запах которой привлек внимание племен гатафан, отправившихся в погоню за братьями».

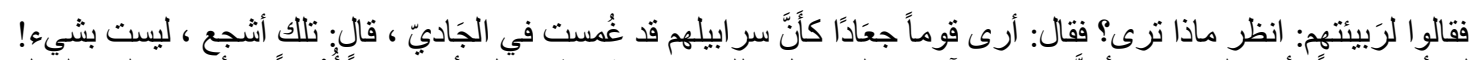

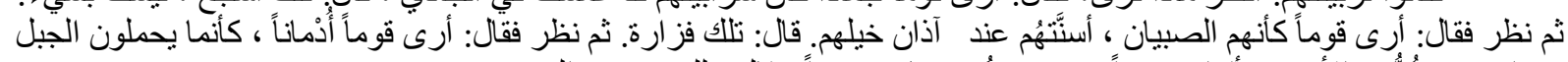

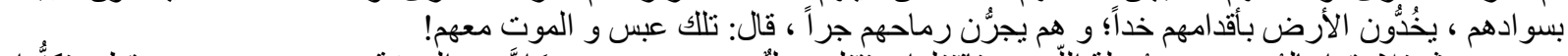

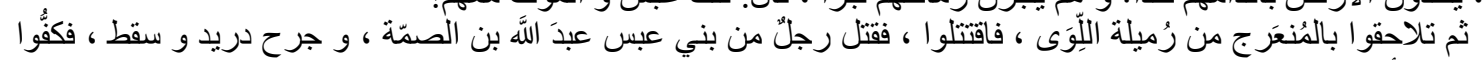

Они говорили своим разведчикам: Посмотри, что ты видишь?

Он ответил: Я вижу много росльх людей, одежда их шафранового ивета.

Он сказал: Это - ал-Ашджа, бесспорно.

Затем он посмотрел и сказал: Я вижу людей, похожих на подростков. Они держат пики на уровне ушей своих коней.

Он ответил: Это Фазара.

Он еще посмотрел и сказал: Я вижу людей темного ивета, как будто гора движется, они бороздят землю своими ногами и волоком тащат свои копья.

Он сказал: Это Абситы, смерть идет с ними.

Затем они догнали друг друга в местечке ал-Мун 'аридж в песках ал-Лива, завязался жестокий бой, в котором было пролито много крови. В этом сражении один из абситов убил Абдаллу ибн ас-Саммата, а Дурайд был ранен и упал, они бросили его, подумав, что он убит...

Подробность этих описаний призвана придать правдоподобие повествованию, и стремление сохранить в памяти как можно более точно прошлое народа и племени ${ }^{2}$. Рассказчик уверен, что он может повлиять на действительность, если умножит численность своего племени, перечислив большее количество его членов и прибавив еще несуществующих героев соплеменников. «Таким образом, здесь мнимая точность как нельзя более естественно сочетается с фантастичностью и в ситуациях, и в определенном количестве, возрасте, внешности героев и так далее» $[12$, с. 66]. Как мы видим события происходят в реальном мире, они обставлены бытовыми подробностями (это есть художественные детали), действующие лица говорят вполне бытовым, характерным для них языком (то есть приближение средств

\footnotetext{
${ }^{1}$ т.е. Аббас-глухой (прим. автора)

2 Хотелось бы обратить внимание на тонкие и точные наблюдения, позволяющие "на глазок”, по едва заметным признакам определить принадлежность к тому или иному племени. В целом, современного читателя в ”Днях" поражает почти фотографическая точность описаний.
} 
изображения к изображаемому), описываются материальные, видимые последствия (то есть исход битв, сражений).

Важную роль в преданиях играют имена собственные, в частности, географические названия. Услышав название знакомой местности, слушателя охватывают определенные эмоции, радость узнавания. В его воображении возникает образ известной долины, селения или горы, мысленно он дополняет то, что опустил в описании сказитель.

Несмотря на то, что «Дни» являются уникальным, ни с чем несравнимым жанром арабской литературы, их, тем не менее, следует относить к эпосу, невзирая на то, что целый ряд признаков отличает предания от других эпических жанров. Так, например, в «Днях» относительно немного эпических преувеличений. Даже совершая героический поступок, его «герой» не выходит за границы человеческих возможностей, хотя иногда, и достигает этого предела. Сражаясь один против нескольких, он побеждает или обращает их в бегство, как, например, персонаж «Дня Сахбал», сражаясь один с четырьмя соплеменниками против семнадцати человек из вражеского племени, убивает почти всех, оставив в живых лишь троих, чтобы, привязав их к верблюдам, отправить к своему племени с посланием [1, с. 242]. Или же в «День ал-Кадид» один из героев убивает троих, защищая честь своей жены [1, с. 241].

Отметим, что в некоторых произведениях от истории остались одни имена героев и правителей, перенесенные в другое эпическое время и эпическое пространство ${ }^{1}$. В «Днях» же действуют люди, некогда жившие на самом деле, они действуют в реальных обстоятельствах, на своей родине, в определенное время, которому нельзя отказать в историчности. Эпическое время «Дней» не может быть определено как условное или фантастическое, оно воспринимается как строго историческое, действительно существовавшее. Вот почему герои «Дней» не наделены вымышленными именами, а действия происходят в реально существовавших местностях, поселениях, городах. Имена героев - в большинстве своем исторические имена, поэтому они так традиционны и устойчивы. И в этом смысле понятны и оправданы поиски в «Днях» исторических прототипов и исторических "протособытий", которые были усвоены более поздними авторами. И здесь ещё раз уместно вспомнить утверждение Б. Шидфар о том, что «"Дни" явились уникальным кладезем сюжетов, оказавшим огромное влияние на развитие средневековой арабской литературы» [12].

Но более всего от других родов эпоса «Дни» отличаются своей стилистикой, изобразительными средствами, которые приближаются к романным. Если некоторые произведения эпоса написаны так, что у читателей создается впечатление определенного барьера, существующего между реальным и изображенным миром, то язык «Дней», простой и обыденный, наоборот, этот барьер разрушает.

«Дни» рождались в обществе, еще не ощущавшем живую связь с миром «Дней» как в историческом, так и генеалогическом, территориальном и культурно-бытовом отношении. Хотя мы привыкли к тому, что обычно в эпосе воспевается далекое прошлое, некоторые из «Дней», такие как «День Зи Кар», «День ал-Уакаба» и другие, были созданы уже в период распространения ислама, и грань в них между изображаемым временем и временем записи почти стёрта.

Итак, резюмируя вышеизложенное, обобщим следующие выводы:

Предания «Аййам ал-араб», являясь, по сути, «местными хрониками», о которых было известно по всей территории Аравии, стали общеарабским достоянием благодаря тому, что «выжили» в силу определенных причин. На наш взгляд, основной из этих факторов сводится к тому, что предметом изображения в преданиях служил не быт, не повседневная жизнь людей, а решающие поворотные моменты в судьбах арабских племен, запечатлевшиеся в народной памяти.

В «Аййам ал-араб» даётся точное (порой до мельчайших подробностей) изображение действительной жизни, реальных конфликтов и ситуаций, героев и персонажей, живших тогда на самом деле. Иначе говоря, между реально существующим и изображаемым миром нет того несоответствия, который присущ некоторым эпическим произведениям. Как следствие этого, в этих преданиях мы не находим вымысла, потому что важным требованием в предании было требование соблюдения точности, что в целом присуще эпосу, и не только арабскому. А

\footnotetext{
1 Здесь речь идет о героических личностях, нередко имеющих исторический прототип: герой «Сират Антара» - известный доисламский поэт и герой Антара ибн Шаддад; центральная фигура «Сират азЗахир Бейбарс» - государственный деятель и храбрый военачальник, султан Египта; главное действующее лицо «Киссат ал-амир Хамза ал-Бахлаван» - Хамза ибн ал-Мутталиб, дядя пророка Мухаммада и т.д..
} 
простой и обыденный, лишенный излишней витиеватости и вычурности, язык героев и повествования ещё раз свидетельствует в пользу данного аргумента.

Что касается особенностей повествования в «Аййам ал-араб» как своеобразной формы литературного произведения, то здесь бросается в глаза так называемый «симбиоз» прозаической части со стихотворной, некое единство прозы и поэзии. Многочисленные события и факты отображаются в большинстве случаев в прозаической форме, а эмоциональная часть повествования сосредоточена в поэтических отрывках, которые зачастую совпадают с предшествующей прозаической частью. Стиль «Аййам ал-араб» сугубо деловой, отличается экономичностью средств, с помощью которых описываются персонажи, освещаются события и другие детали. Все события и предметы описываются кратко, но очень насыщенно, и обязательно имеют отношение к рассказу о конфликте, столкновении, мести и т.д. И главное, на наш взгляд, правило эпических повествований, в том числе и этих преданий, состоит в том, события излагаются в однолинейной временной последовательности, то есть, нет здесь возврата в прошлое или «забегания» вперёд.

Как и в большинстве преданий, в «Аййам ал-араб» собственно героическая тематика с её поединками и сражениями всегда на первом плане повествования. Конфликты, распри, междоусобицы - это, по сути, конфликты между людьми, обусловленные столкновением их интересов, и выявляющие качества и характеры их участников. Однако, об оттенках психологизма, раскрытии положительных и отрицательных черт, об изображении разносторонности характера персонажей говорить ещё не приходится, ибо сложность человеческого характера не вписывалась в рамки традиционно героического содержания и традиционные способы изображения.

\section{ЛИТЕРАТУРА}

1.

2. Аверинцев С.С. Мифы // Краткая литературная энциклопедия / Под ред. А. А. Суркова. - М., 1972. T. 4. - С. 876-881.

3. Веселовский А.Н. Историческая поэтика. - М., 1989. - 405 с.

4. Дьяконов И.М. Архаические мифы Востока и Запада. - М.: Наука, 1990. - 246 с.

5. Жирмунский В.М. Народный героический эпос.- М.-Л., 1962. - 435 с.

6. Жирмунский В.М., Зарипов Х.Т. Узбекский народный героический эпос.- М., 1947. (элекронный вариант)

7. Ибрагимов Н.И. Арабский народный роман. - М., 1984. -255 с.

8. Лихачев Д.С. Поэтика древнерусской литературы. - М., 1979. - 360 с.

9. Лотман Ю.М. Статьи по типологии культуры. - Тарту, 1973. - 150 с.

10. Мухтаров Т.А. Жанры средневековой арабской прозы (СИРА)/ Отв. ред. Н.Ибрагимов. - Т., 2010. - 96 с.

11. Мухтаров Т.А., Саттиев А.И., Шамусаров Ш.Г. Очерки средневековой арабской прозы.- Т., 1992. - 219 с.

12. Шидфар Б.Я. Образная система арабской классической литературы (VI-XII вв.). - М., 1974. - 254 с. 